\title{
Assessment of Particles of Varied Soil By Grain Size Analysis - A Case Study in Jabalpur M.P.
}

\author{
Sanjay Kumar Verma*,Dr. Saleem Akhtar**,Sagar Shrivastava***, \\ * (Head, Department of Civil Engineering, TIETECH, Jabalpur - 482002, M.P. India) \\ ** (Prof. Department of Civil Engineering UIT, RGPV, Bhopal-462003, M.P. India) \\ *** (Student, IIIrd year, Civil Engineering, TIETECH, Jabalpur-482002, M.P. India) \\ Corresponding author: Sanjay Kumar Verma*
}

\begin{abstract}
:
Grain size distribution plays a vital role for characterization of soil. Particle size distribution (PSD) in a soil mass is a character which gives a major idea about bearing capacity of soils and bearing capacity of the soil is a key parameter to design foundation of any civil engineering structure. Indian Standards has classified the soils as per particle size gradation. As per I S Code range of the particle size varies from boulder to clay. This paper discusses about the results of particle size distribution of varied soil stratum at a construction location in Jabalpur M.P. Present paper also suggests some recommendations about types of foundation and suitable methods for ground improvement .
\end{abstract}

Keywords: Indian Standards, P.S.D., M.S.W., Soil Stabilization, Particle Size, C.P.R.F.

Date of Submission: 21 -07-2017

Date of acceptance: $31-07-2017$

\section{INTRODUCTION}

Particle size distribution also known as gradation, refers to the proportions by dry mass of a soil distributed over specified particle-size ranges. Gradation is used to classify soils for engineering and agricultural purposes. Knowing the grain size distribution of a soil is important for a variety of reason and for a range of uses constructions. Grain sizes of the soil reflect directly on so many other parameters of the soil e.g. specific gravity, porosity, permeability, void ratio and give a general idea about

\section{GRAIN SIZE OF SOIL}

Grain size of the soil varies from its upper limit boulder to its lower limit clay. Classification according to IS: 1498- 1970 classification and identification of the soil for general engineering purpose have done in the field of buildings. Soil investigation and classification is the soil as regards its bearing power to a certain extent. Soil bearing capacity of the soil. Ground water table is also very much depends upon the type of grains present in the soil mass. Grain size analysis of soil is an important parameter for soil exploration. Particle size analysis is a prime laboratory test for classification of soils. Analysis of grain size is equally important for civil engineering structure e.g. Roadwork, Dam, Water reservoir, Marine structures, Building Structure. This paper presents a case study of grain size analysis of soil for construction of a building structure in Jabalpur M.P.

classification is a medium of communication among soil engineers for geotechnical practices. This differentiates the coarse grained and fine grained soils. This also provides the basis for detailed geotechnical investigations. As per the Indian Soil Classification in general the soils are classified as mentioned in table 1 according to their grain sizes

Table 1 Soil classification as per Indian soil classification (ISC) I.S. 1498 - 1970

\begin{tabular}{|c|l|l|}
\hline S No. & Type of Soil & Size of Grains \\
\hline 1 & Boulder & above $300 \mathrm{~mm}$ \\
\hline 2 & Cobble & $300-75 \mathrm{~mm}$ \\
\hline 3 & Coarse Gravel & $75-20 \mathrm{~mm}$ \\
\hline 4 & Fine Gravel & $20-4.75 \mathrm{~mm}$ \\
\hline 5 & Coarse Sand & $4.75-2 \mathrm{~mm}$ \\
\hline 6 & Medium Sand & $2.0-0.425 \mathrm{~mm}$ \\
\hline 7 & Fine Sand & $0.425-0.075 \mathrm{~mm}$ \\
\hline 8 & Silt. & $0.075-0.002 \mathrm{~mm}$ \\
\hline 9 & Clay & below $0.002 \mathrm{~mm}$. \\
\hline
\end{tabular}


Table 2. Distribution of Grain Sizes as per I.S. 1498 - 1970

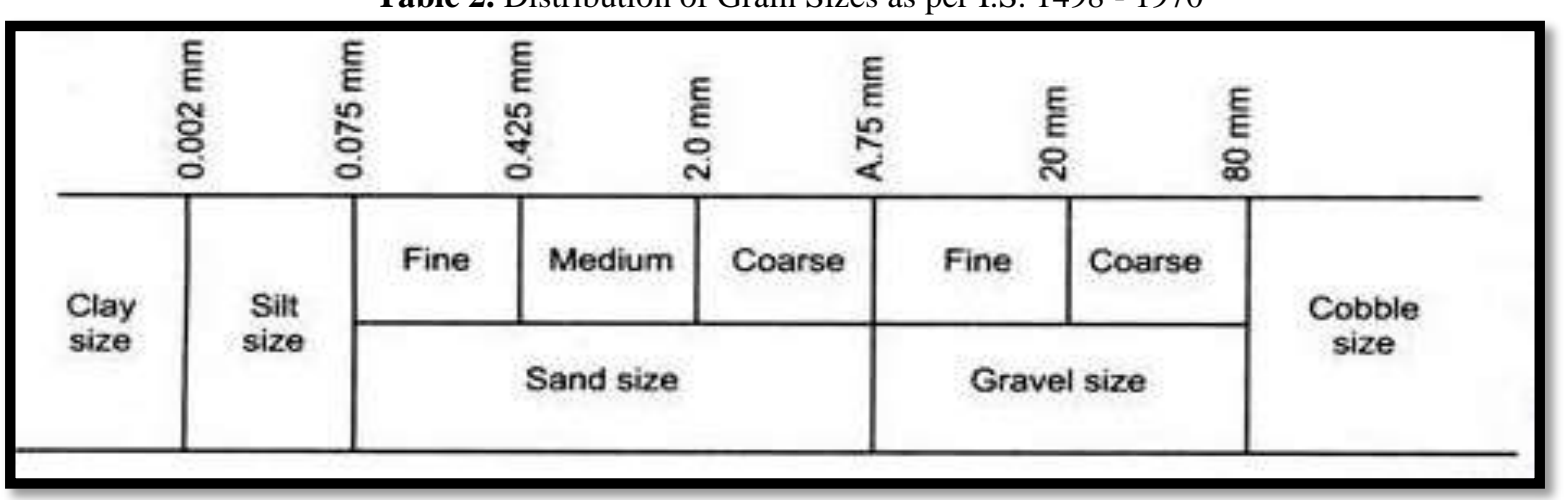

\section{GRAIN SIZE ANALYSIS OF SOIL} AS PER IS: 2720 (PART 4) - 1985

The particle size distribution of a coarse grained soil is generally determined using a sieve analysis where a prepared dry soil sample is shaken thoroughly through a stack of sieves that consist of different apertures. The mass of particles retained on each sieve is calculated as a percentage of the total dry sample mass. The grain size distribution of the fines less than $75 \mu \mathrm{m}$ is determined using hydrometer analysis where the fines are combined with distilled water to form a $1000 \mathrm{ml}$ of suspension. The hydrometer is used to measure the density of this solution for specific times. This time-density data is then used to calculate the percentage of different particle sizes for the required 48 hour period where observations are required to be made. It is quite common for soils to contain both coarse and fine grains and it is necessary to undertake both a sieve and hydrometer analysis to obtain the complete particle size distribution. The usual method followed is to initially carry out a sieve analysis, which is then followed by the hydrometer test on the particles that pass the $75 \mu \mathrm{m}$ sieve. The percentage passing each

\section{CASE STUDY}

A study for determination of grain size has been done by the author during the exploration of soil for a construction site at Jabalpur M.P. This was a site for construction of a $(\mathrm{G}+4)$ private building. This site found some troublesome, because the location was a edge of a lake reclaimed earlier by the municipal solid waste (MSW) and detritus garbage waste material for obtaining the land. On the preliminary observation by checking through trial pits and trial trench, this was estimated that the selected location for the construction is filled with the waste material. Further various field tests and laboratory tests were executed for complete geotechnical investigation. Grain size analysis was a part of this soil exploration. Total 4 points has been analyzed on a plot area measured 1000 SqM. Result of the grain size analysis were found more are less similar in all these 4 points, so that results of only one borehole (BH1) up to 15 sieve is generally treated cumulatively to determine the entire particle size distribution. An analysis of this kind express quantitatively the proportions by mass of the various sizes of particles present in the soil. In a soil the gravel, sand silt and clay fractions are recognized as containing particles of decreasing magnitude. The actual ranges of dimensions of the particles are given in table 2 . The results of a grain size analysis may also be represented graphically in the form of a grain size distribution curve in which the cumulative percentages finer than known equivalent grain sizes are plotted against these sizes on a semi logarithmic scale. IS 2720 (Part 4) covers the method for the quantitative determination of grain size distribution in soil. Two methods are given for finding the distribution size larger than 75-micron the, first method, wet sieving shall be applicable to all soils and the second, dry sieving, shall be applicable only to soils which do not have an appreciable amount of clay. For the determination of distribution of grain sizes smaller than 75-microns the pipette method is given as the standard method; the hydrometer method is given as a subsidiary method. This method shall not applicable if less than 10 percent of the material passes the 75-micron.

meter depth are analyzed in this paper. On the basis of the preliminary observation by executing trial pits, trial trench and test piles it has been found that approximately upper $5-6$ meter depth is filled by municipal solid waste and city garbage. Sample of the soil withdrawal with the help of hand driven and machine driven augur pile bore. Sample were collected from each borehole and execute grain size analysis soil test at laboratory according to IS: 2720 (Part 4) -1985 


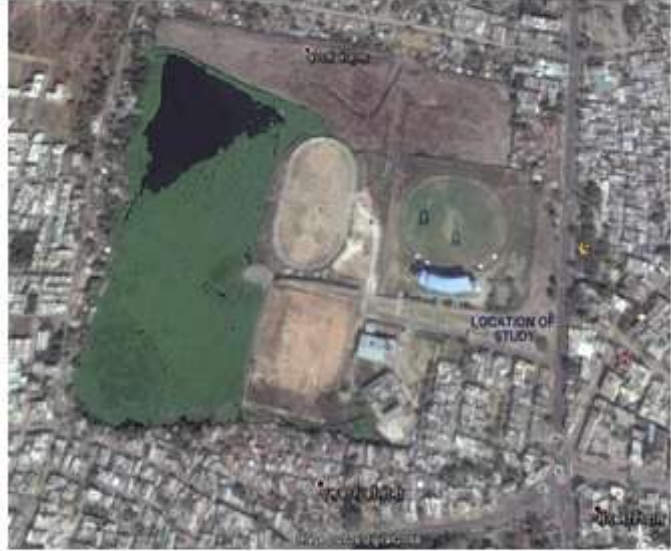

Figure 1 Satellite imagery of study area (Source Google Earth)

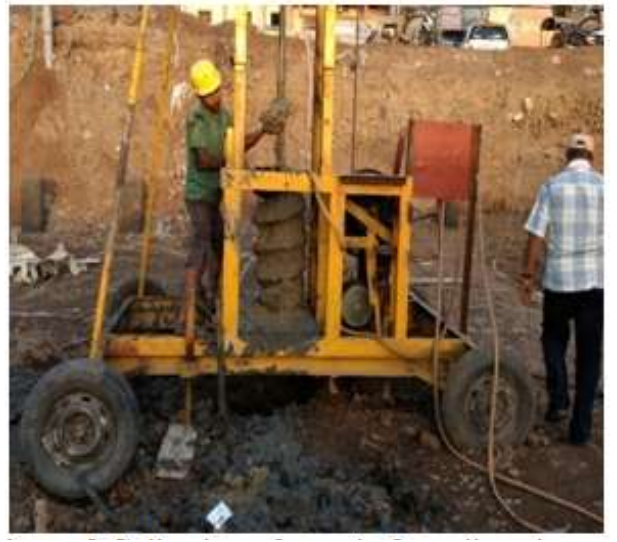

Figure 2 Collection of sample for soil testing
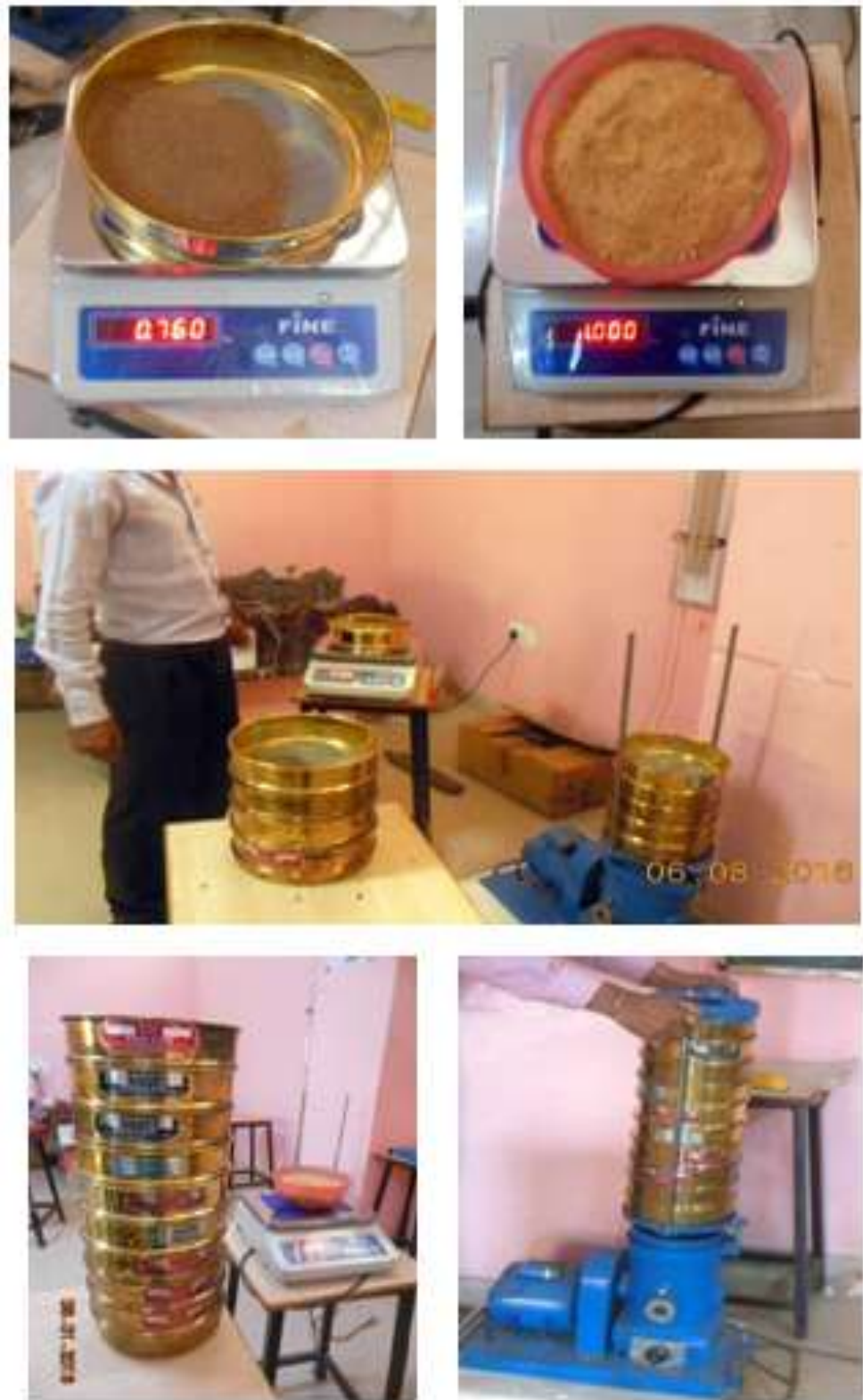

Figure 3 Laboratory tests for grain size determination of soils 

ISSN : 2248-9622, Vol. 7, Issue 7, ( Part-9) July 2017, pp.32-37
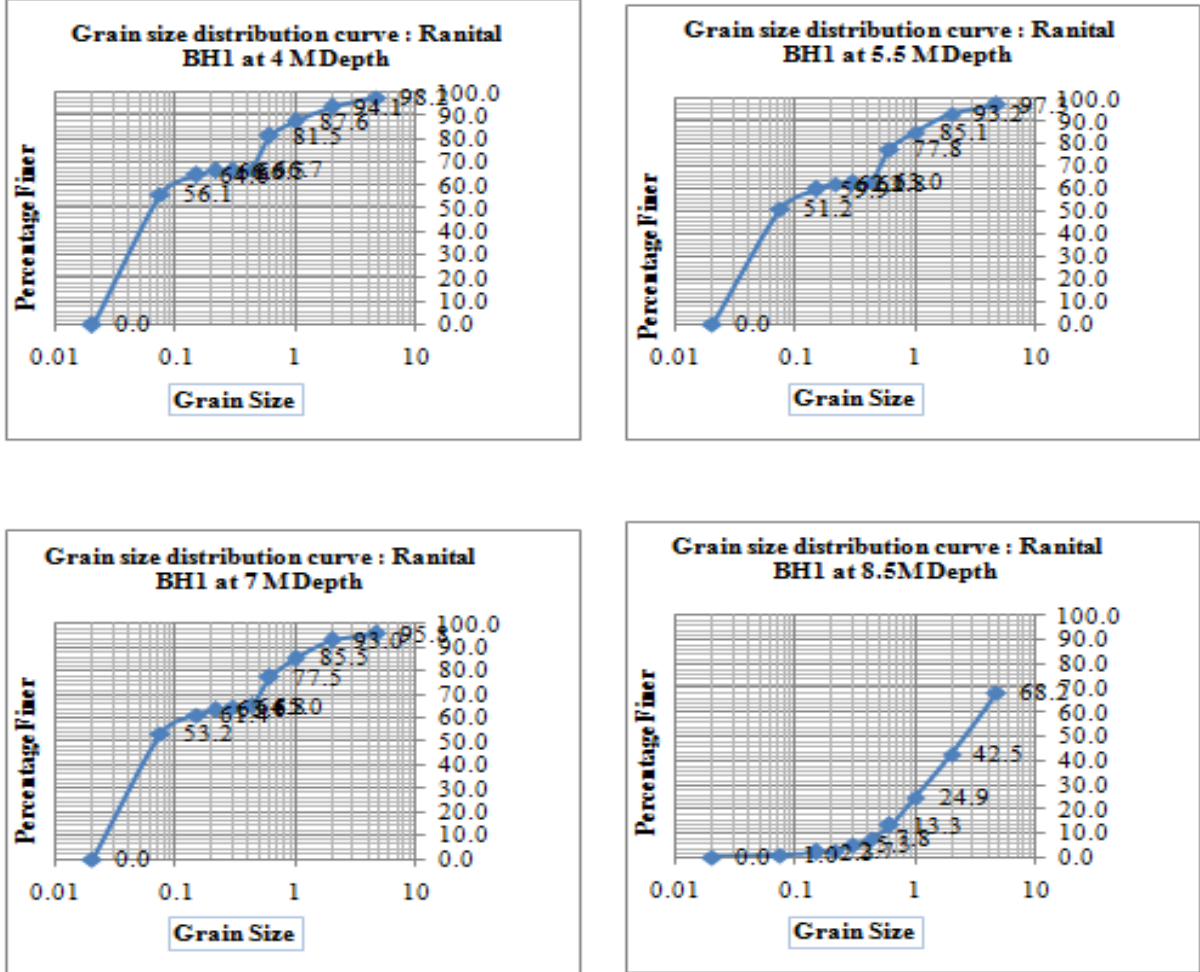

Figure 4 Grain Size Distribution Curve for soil sample between 4 M - 8.5 M Depth in BH1
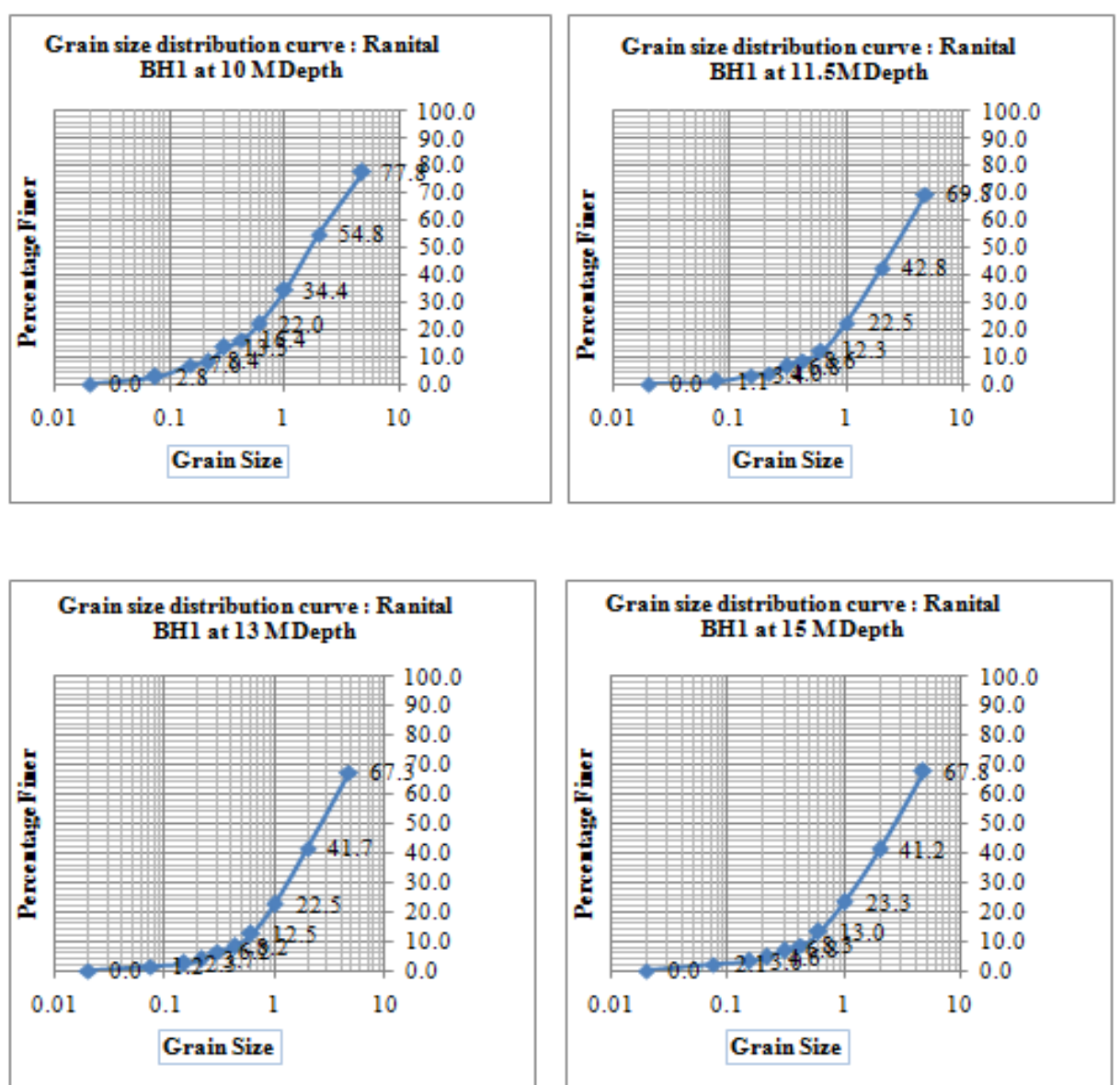

Figure 4 Grain Size Distribution Curve for soil sample between 10 M - 15 M Depth in BH1 

ISSN : 2248-9622, Vol. 7, Issue 7, ( Part -9) July 2017, pp.32-37

\begin{tabular}{|c|c|c|c|c|c|c|c|c|}
\hline \multicolumn{7}{|c|}{ Table 3. Grain Size Analysis } \\
\hline \multicolumn{7}{|c|}{ Classification Of Soil As Per Grain Size Analysis } \\
In (Bh1) At Ranital (Is: 1498- 1970)
\end{tabular}

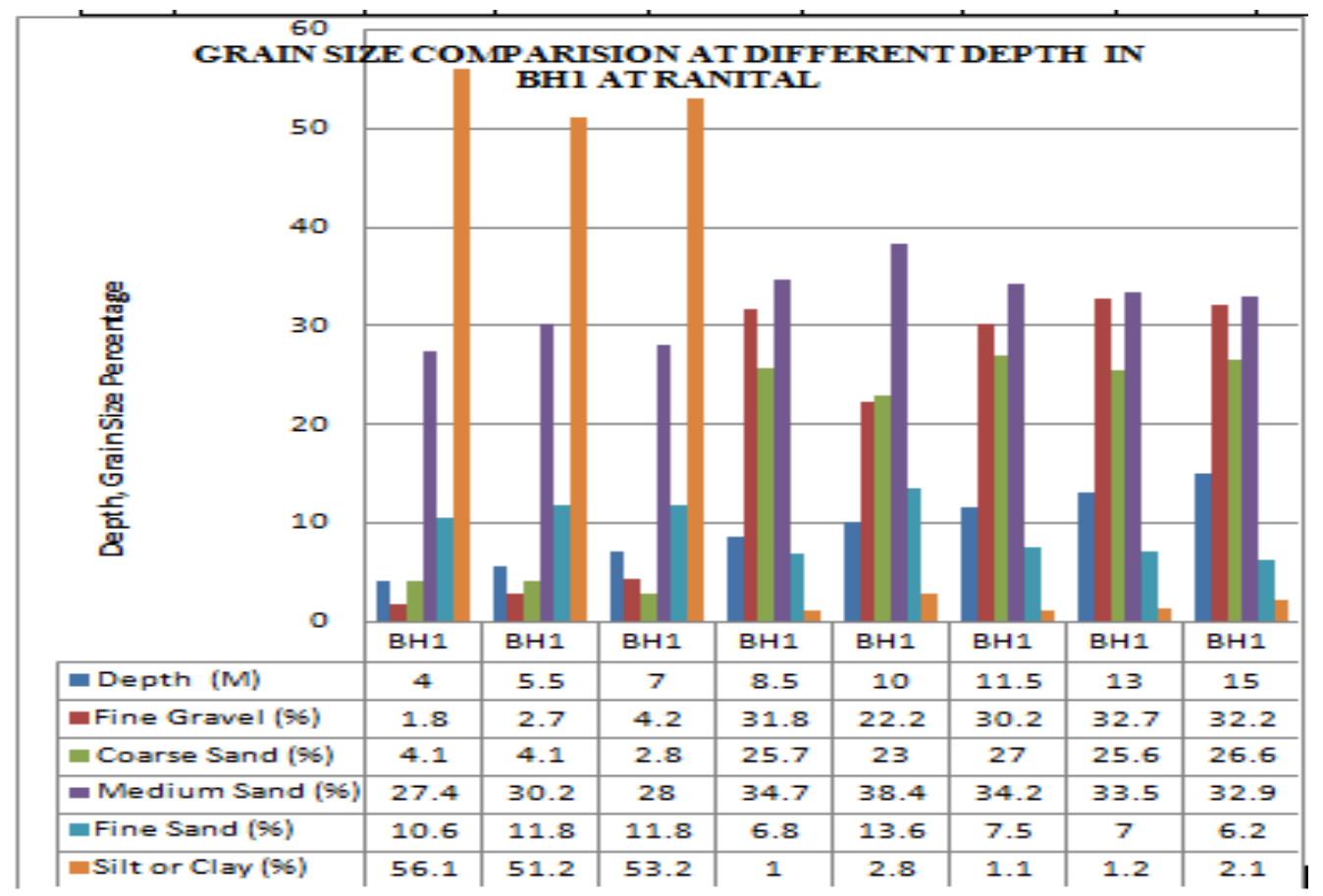

Figure 5 Grain Size Comparison in BH1at Ranital

\section{RESULTS AND CONCLUSION}

Following general conclusions can be drawn from the present study.

i. Average 4 meter upper depth of the site at Ranital location is filled with the municipal solid waste (MSW) and other waste material. Hence this stage is not favorable for erection of foundation.

ii. Upper $4 \mathrm{M}$ to $7.5 \mathrm{M}$ depth of the stratum is cohesive soil i.e. clay and silt type. Hence soil in this depth is fine grained soil. For determination of the percentage of clay or silt, further hydrometer test can be applied.

iii. Soil between the depths $7.5 \mathrm{M}$ to $15 \mathrm{M}$ is found cohesion less soil. This soil has percentage of sand more than $50 \%$, hence soil between this depth is coarse grained type.

iv. Atterbergs's limit i.e. Liquid limit and Plasticity Index analysis is required for classification of the fine grained soil between the depths $4 \mathrm{M}-7.5 \mathrm{M}$. With the help of plasticity chart (IS: 1498-1970) soil classification can be completed.

\section{RECOMMENDATIONS}

i. Upper 4 meter depth of the site is found filled with municipal solid waste (MSW) which may be harmful for any structure, if foundation constructed directly over it without ground improvement. This will be better to remove all waste matter before making foundation. 
ii. Stratum between the depths $4 \mathrm{M}$ to $7 \mathrm{M}$ should be properly improved. Soil stabilization can be done by any suitable method recommended by Indian Standard for cohesive or soft soil.

iii. Deep pile foundation or group pile foundation (as per structural need) will be suitable as foundation type. Looking to the site condition Combined Pile Raft Foundation (CPRF) is also suggested.

\section{REFERENCES}

[1]. IS 1498: 1970, "Classification and Identification of Soils for General engineering purposes", Reaffirmed 1987.

[2]. IS 1904: 1986: "Code of Practice for Design and construction of foundation in soils: general requirements (3rd edition)".

[3]. IS 2720 (Part 4): 1985 Methods of test for soils Part 4 "Grain sixe analysis second revision)".

[4]. IS 2720 (Part 5): 1985 Methods of test for soils: Part 5 "Determination of liquid and plastic limit (second revision)" Reaffirmed 1990 CED 23.

[5]. Singh, Alam (1981), "Soil engineering in theory and practice". Asia Publishing House, Bombay.

[6]. Singh, Bharat, Prakash, S. (1982). "Soil mechanics and foundation engineering". Nem Chand and Bros. Roorkee.

International Journal of Engineering Research and Applications (IJERA) is UGC approved Journal with Sl. No. 4525, Journal no. 47088. Indexed in Cross Ref, Index Copernicus (ICV 80.82), NASA, Ads, Researcher Id Thomson Reuters, DOAJ.

Sanjay Kumar Verma. "Assessment of Particles of Varied Soil by Grain Size Analysis - A Case Study in Jabalpur M.P." International Journal of Engineering Research and Applications (IJERA) 7.7 (2017): 32-37. 